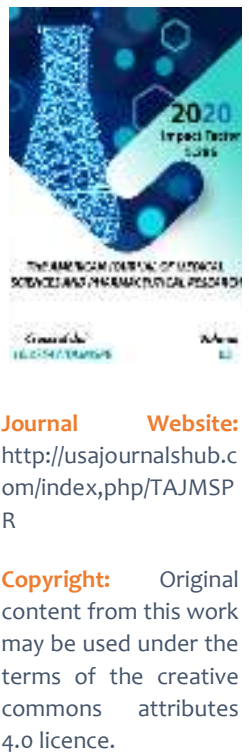

\title{
Optimization Of Allergic Rhinitis Therapy In Children
}

\author{
Mirrakhimova Maktuba Khabibullayevna \\ Candidate Of Medical Sciences, Senior Lecturer, First Children's Diseases Department, \\ Tashkent Medical Academy, Tashkent, Uzbekistan \\ Saidkhonova Adibakhon Murotkhonovna \\ Assistant, First Children's Diseases Department, Tashkent Medical Academy, Tashkent, \\ Uzbekistan
}

\section{ABSTRACT}

The article considers the problems of optimization of allergic rhinitis complex therapy efficiency in children with the help of Nikazoline $0.05 \%$ spray and nasal drops produced by Nika pharm Ltd. in Uzbekistan compared to other agents containing xilometazoline.

\section{KEYWORDS}

Children, allergic rhinitis, Xylometazoline, efficacy, tolerance.

\section{INTRODUCTION}

Nowadays in the whole world there is notable growth of allergic diseases prevalence, conditioned by a rapid improvement of socialeconomical conditions of life on one side, and the impact of ecologically unfavorable factors on the other $[5,8,9]$. According to World Health Organization (WHO) data allergic diseases' prevalence occupies the third place now, and it is predicted, that by 2050 it will take the first place in the structure of total morbidity. Epidemiological studies of allergic pathologies testify their high prevalence rate in various regions of the world: average from 10 to $30 \%$ of the earth population suffer various forms of allergic diseases. At the same time, there is explicit tendency for annual increase of the 
prevalence rate $[1,5,6]$. It is known, that allergic rhinitis (AR) causes decrease of the quality of life, provokes development of other ENT pathologies (sinusitis, middle otitis, eustachitis, nasal polyposis, infections of the upper respiratory ways). Recently its close relation to bronchial asthma became obvious. WHO evidence-based document Allergic rhinitis and its impact on asthma (ARIA) is also dedicated to that problem. It was shown, that allergic rhinitis and bronchial asthma are manifestations of one and the same pathology of respiratory ways. Thus, allergic rhinitis should not be considered as a harmless condition. That pathology not only significantly effects patient's quality of life, but also serves to be a predictor and predisposition factor for the development of more severe diseases $[9,10]$. In case of incorrect therapy rhinitis can relapse more than ten times a year $[2,3,4,7]$. From our point of view, development of new complex methods of allergic rhinitis therapy in children will provide the improvement of efficacy of the therapy of that pathology, and, consequently, prevention of more severe allergic diseases. Exactly that opinion determined the objective and aims of the study.

\section{THE OBJECTIVE}

To optimize the efficacy of allergic rhinitis complex therapy in children with the help of Nikazolin spray and $0.05 \%$ nasal drops produced by «Nika pharm» Ltd. In Uzbekistan in comparison with Xylometazoline $0.05 \%$ nasal spray (Flumed-pharm Ltd., Moldova) and Pharmazoline $0.05 \%$ nasal drops (Pharmak JSC, Ukraine) for possible recommendation of the agent for clinical application in the Republic of Uzbekistan.

\section{MATERIALS AND METHODS}

The study was performed among the patients receiving in and out-patient therapy in the units of clinics and polyclinic at the First Department of Children's Diseases of TMA. The decision of the Pharmacological Committee Chair (minutes of meeting № 29 dated 03.10.2018). In the group receiving the studied agent, and in the group receiving comparison agent there were 20 patients in each. Groups were composed according to age, gender, and the diagnosis (Table №1).

\section{Table №1}

\begin{tabular}{|l|l|l|c|c|}
\hline \multicolumn{2}{|c|}{ Group } & \multicolumn{1}{|c|}{ Gender } & Mean age & Allergic rhinitis \\
\hline \multirow{3}{*}{ Basic groups } & Nikazoline & 17 boys & $3.4 \pm 0.1$ & 20 \\
& $0.05 \%$ spray & 3 girls & & \\
\cline { 2 - 5 } & $\begin{array}{l}\text { Nikazoline } \\
0.05 \% \text { drops }\end{array}$ & $\begin{array}{l}12 \text { boys } \\
8 \text { girls }\end{array}$ & $3.1 \pm 0.1$ & 20 \\
\hline & $\begin{array}{l}\text { Xylometazoline } \\
0.05 \% \text { spray }\end{array}$ & $\begin{array}{l}12 \text { boys } \\
\text { 8girls }\end{array}$ & $3.7 \pm 0.5$ & 20 \\
\hline
\end{tabular}




\begin{tabular}{|l|l|l|c|c|}
\hline $\begin{array}{l}\text { Control } \\
\text { group }\end{array}$ & $\begin{array}{l}\text { Pharmazoline 0.05\% } \\
\text { drops }\end{array}$ & $\begin{array}{l}11 \text { boys } \\
9 \text { girls }\end{array}$ & $3.4 \pm 0.2$ & 20 \\
\hline
\end{tabular}

Inclusion criteria were: patients of both genders in the age from 2 to 6 years old diagnosed with allergic rhinitis.

Criteria of not inclusion were as follows:

- $\quad$ age under 2 and above 6;

- counter indications to prescription of xylometazoline;

- arterial hypertension

- tachycardia

- atrophic rhinitis;

- necessity of application of drugs incompatible to xylometazoline;

- participation of the patients in other clinical trials within the last 30 days;

- absence of informed written consent to participate in the clinical trial.

- Exclusion criteria:

- patient's refusal or no possibility to follow the protocol;

- necessity of prescription of agents inappropriate to the given study frames;

- development of unfavorable phenomena requiring cancellation of the agent;

- the wish of a patient to finish the study ahead of schedule due to any reason;

- cases, not stipulated in the protocol, when the researcher considers that further participation of the patient in the study can be harmful for his health;

- inclusion of inappropriate patients to the study by mistake.

For the distribution of the studied patients to the groups we used simple randomization method. Original table of patients distribution was formed on the basis of random numbers received with the help of random numbers generation function MS Excel, and possessed by the sponsor. Distribution itself was performed on the basis of sealed envelopes provided by the sponsor. After the inclusion of patient and giving him/her a number an envelope with the corresponding number was opened with the further prescription of the therapy described in that envelope.

Patients of the basic group (40) received intra nasal injection of Nikazoline $0.05 \%$ spray or $1-2$ drops to each nasal way twice a day produced by Nika Pharm Ltd. In Uzbekistan (20 patients received nasal drops and 20 patients nasal spray). Twenty patients of the comparison group received Xylometazoline $0.05 \%$ spray produced by Flumed-Pharm Ltd. In Moldova, while other 20 patients from this group were prescribed Pharmazoline $0.05 \%$ drops (Pharmak JSC, Ukraine) in compliance with the same scheme. Xylometazoline (trade name: Nikazoline) has alpha-adrenomimetic effect and causes narrowing of peripheral vessels. As a consequence of vessel-narrowing effect it diminishes edema and hyperemia of nasal mucous membrane. It decreases secretion, restores permeability of nasal pathways, and facilitates nasal breathing. It also eliminates runny nose and nasal congestion. Its effect is notable in few minutes and lasts for several hours.

Additional therapy types: we excluded any other agents with similar effect. We used agents necessary for the therapy of the basic pathology (NSAIDs, antibiotics, bronchodilator agents) and other preparations, compatible to the agent, and particularly, according to indications. After the original check-up, patients correspondent to the inclusion criteria 
Doi: https://doi.org/10.37547/TAJMSPR/Volume02Issue08-19

, their parents or legal representatives were informed about the agent, its doses, ways of injection, and the therapy period in order to receive a written consent to participate in the study.

After receiving of the written consent from parents of legal representatives a child was prescribed the studied or comparison agent. The start point of a patients' participation in the study was the first day of the agent administration. Performed therapy was detail described for all patients included in the study. Any therapy relevant to the concomitant pathology was registered in case history and individual registration form.

\section{Results And Discussion}

Assessment of the efficacy of the studied agent was performed on the basis of the aforesaid criteria according to the following scale scores:

\begin{tabular}{|c|c|c|}
\hline $\begin{array}{c}3 \\
\text { points }\end{array}$ & High efficacy rate & $\begin{array}{l}\text { Expressed leveling of the symptoms at the end of the therapy } \\
\text { course (absence of rhinorrhea, no nasal congestion, free nasal } \\
\text { breathing). }\end{array}$ \\
\hline $\begin{array}{c}2 \\
\text { points }\end{array}$ & $\begin{array}{l}\text { Moderate efficacy } \\
\text { rate }\end{array}$ & $\begin{array}{l}\text { Significant leveling of the symptoms (moderate improvement of } \\
\text { nasal breathing, absence of rhinorrhea) at the end of the therapy } \\
\text { course. }\end{array}$ \\
\hline $\begin{array}{c}1 \\
\text { point }\end{array}$ & Low efficacy rate & $\begin{array}{l}\text { Insignificant decrease in the symptoms at the end of the therapy } \\
\text { course, insignificant improvement of nasal breathing, preservation } \\
\text { of rhinorrhea symptoms. }\end{array}$ \\
\hline $\begin{array}{c}0 \\
\text { points }\end{array}$ & No efficacy & $\begin{array}{l}\text { No changes or deterioration of clinical and laboratory parameters at } \\
\text { the end of the therapy course. }\end{array}$ \\
\hline
\end{tabular}

Table 2

Dynamic clinical manifestations of rhinitis

\begin{tabular}{|c|c|c|c|c|c|c|c|c|}
\hline \multirow[t]{2}{*}{ Symptoms } & \multicolumn{2}{|c|}{$\begin{array}{l}\text { Nikazoline spray } \\
\qquad \mathbf{n}=\mathbf{2 0}\end{array}$} & \multicolumn{2}{|c|}{$\begin{array}{l}\text { Nikazoline drops } \\
\qquad \mathbf{n}=\mathbf{2 0}\end{array}$} & \multicolumn{2}{|c|}{$\begin{array}{c}\text { Xylometazoline } \\
\text { spray } \\
\text { n }=20\end{array}$} & \multicolumn{2}{|c|}{$\begin{array}{l}\text { Pharmazoline } \\
\text { drops } \\
n=20\end{array}$} \\
\hline & before & after & before & after & before & after & before & after \\
\hline Runny nose & $1.8 \pm 0.06$ & $0.01 \pm 0.0$ & $1.8 \pm 0.06$ & $0.0 \pm 0.00$ & $1.8 \pm 0.06$ & $0.01 \pm 0.0$ & $1.8 \pm 0.6$ & $0.01 \pm 0.0$ \\
\hline Sneezing & $2.1 \pm 0.08$ & $0.02 \pm 0.0$ & $2.1 \pm 0.08$ & $0.1 \pm 0.0$ & $2.1 \pm 0.08$ & $0.0 \pm 0.00$ & $2.1 \pm 0.8$ & $0.0 \pm 0.0$ \\
\hline
\end{tabular}


The American Journal of Medical Sciences and Pharmaceutical Research (ISSN - 2689-1026)

Published: August 30, 2020 | Pages: 119-125

Doi: https://doi.org/10.37547/TAJMSPR/Volumeo2Issue08-19

\begin{tabular}{|l|l|l|l|l|l|l|l|l|}
\hline $\begin{array}{l}\text { Nasal } \\
\text { congestion }\end{array}$ & $3.6 \pm 0.0$ & $0.03 \pm 0.0$ & $2.5 \pm 0.05$ & $0.01 \pm 0.0$ & $2.4 \pm 0.06$ & $0.0 \pm 0.00$ & $2.5 \pm 0.3$ & $0.0 \pm 0.0$ \\
\hline \multicolumn{10}{|c|}{ P } & \multicolumn{8}{|c|}{$<0.001$} & & & & & & \\
\hline
\end{tabular}

Symptoms manifestation degree was expressed in the following scores:

$$
\begin{array}{cr}
0 \text {-no symptom } & 2 \text { - moderate } \\
1 \text { - slightly expressed } & 3 \text {-expressed }
\end{array}
$$

From Table 2 it is seen, that according to the expression degree patients were more concerned about runny nose and rhinorrhea. All patients had reliable decrease of eosinophiles number in peripheral blood within the second week of the therapy (Table №3).

After the therapy course in all groups the symptoms such as runny nose and rhinorrhea disappeared.

Table 3

Dynamic number of eosinophiles in blood (\%)

\begin{tabular}{|c|c|c|}
\hline \multirow{2}{*}{} & \multicolumn{2}{|c|}{ Agents } \\
\cline { 2 - 3 } & \multicolumn{2}{|c|}{ Eosinophiles \% } \\
\cline { 2 - 3 } & Before therapy & After therapy \\
\hline Nikazoline spray $n=20$ & $4.9 \pm 0.20$ & $2.3 \pm 0.2$ \\
\hline Nikazoline drops $n=20$ & $5.1 \pm 0.20$ & $2.9 \pm 0.3$ \\
\hline Xylometazoline spray $n=20$ & $5.4 \pm 0.20$ & $3.1 \pm 0.12$ \\
\hline Pharmazoline drops $n=20$ & $6.2 \pm 0.20$ & $2.1 \pm 0.2$ \\
\hline
\end{tabular}

In the basic and comparison groups there were no notable side-effects. Both agents had no negative effect on the common blood and urine analyses. Tolerance of the agent was evaluated on the basis of subjective symptoms and feelings informed by a patient independently taking into account objective data obtained by a doctor. We considered dynamic laboratory parameters, frequency and character of side-effects. Assessment of the tolerance of the studied agents was performed on the basis of the aforesaid criteria in compliance with the score scale from 0 to 4 points. 
Performed study showed, that dynamic change of the number of erythrocytes and leukocytes, ESR within the whole period of the trial reliably varied within the physiological limits, except some increase of eosinophiles number in blood before the start of the therapy. The agents were well tolerated; among the patients there were no subjective complaints about the change in health status.

Summarizing the obtained results and after the analysis we calculated the values of agents' efficacy and tolerance, indicating the equivalence of their effect in the studied patients (Table 4).

Table 4Assessment of the efficacy and tolerance of the agents

\begin{tabular}{|c|c|c|}
\hline Agent & Efficacy & Tolerance \\
\hline Nikazoline spray & $2.8 \pm 0.1$ & $4.0 \pm 0$ \\
\hline Nikazoline drops & $2.8 \pm 0.05$ & $4.0 \pm 0$ \\
\hline Xylometazoline spray & $2.9 \pm 0.01$ & $3.9 \pm 0.1$ \\
\hline Pharmazoline drops & $3.0 \pm 0.0$ & $4.0 \pm 0$ \\
\hline
\end{tabular}

\section{CONCLUSION}

1. Obtained results let us conclude, that Nikazoline $0.05 \%$ nasal spray and drops produced by Nika pharm in Uzbekistan are effective in the therapy of patients with rhinitis.

2. Our experience of application of Nikazoline $0.05 \%$ nasal spray and drops showed, that it has sufficient clinical activity, efficacy, good tolerance, and it can be recommended for the registration and medical application in the Republic of Uzbekistan.

\section{REFERENCES}

1. Allergic rhinitis in children. Recommendations and algorithm in case of pediatric allergic rhinitis.
Scientific-practical [Allergicheskiirinit

program udeteirekomendatsiiialgoritmpridetsk omallergicheskomrinite] Edit. By V.A. Revyatkin, N.A. Daykhes, N.A. Geppe. M., 2015. (in Russian)

2. Belova O.I., Belov V.A. Antihistamine therapy of allergic rhinoconjunctivitis in children [Antigistaminnayaterapiyapriallergiche skomrinokonyuktiviteudetei] Medical advice, 2015, 6: 84-87. (in Russian)

3. Karpova Y.P., Tulupov D.A. Local therapy of infectious complications of allergic rhinitis in children [Mestnayaterapiyainfektsionnihoslojn eniiallergicheskogo rinitaudetei] Otolaryngology bulletin, 2013, 5: 73-76. (in Russian) 
4. Gell PGH, Coombs RR. Clinical aspects of immunology. Oxford: Blackwell, 1963: 317-320.

5. Jae W.Ch. Khalmatova B.T., Salomova F.I., Razikova I.S., Mirraximova M.H. The prevalence of symptoms of allergic diseasesin children residing in industrialregions of Uzbekistan //International Journal of Psychosocial Rehabilitation 2020. Volume 24 - Issue 4. pp: 2105-2115

6. Kurbanova D.R., Mirrakhimova M. Kh. Improving diagnostic methods for detecting allergic diseases in children // Journal of biomedicine and practice. 2020.- №SI.: 522-530.

7. Mirrakhimova M. Kh. Improving methods of treatment of atopic pathology in children //Journal of Critical Reviews 2020. Volume 7 - Issue 12. pp: 190-192.

8. Mirrakhimova M.K.et al.: Characteristics of Allergic Pathologies Progression in Young Children //American Journal of Medicine and Medical Sciences 2020, 10(9): 652-656

9. Mirrakhimova M. Kh., Saidkhonova A. $M$. Frequency of atopic diseases in unfavorable ecological regions of Uzbekistan // Problems of biology and medicine 2020, №2 (118): 84-87

10. Roberts G, Xatzipsalti M, Borrego L, Custovic $A$ et al. Paediatric rhinitis: position paper of the European Academy of Allergy and Clinical Immunology. Allergy, 2013, 68: 11021116. 